Aletria, Belo Horizonte, v. 28, n. 1, p. 61-82, 2018

\title{
Morte, ressurreição ou superação do romance?
}

\section{Death, ressurrection or enhancement of the novel?}

\author{
Fabrício Tavares Moraes \\ Universidade Federal de Juiz de Fora, Juiz de Fora, Minas Gerais / Brasil \\ fabriciotavaresm@gmail.com
}

Resumo: O presente artigo busca analisar panoramicamente as transformações formais e circunstâncias históricas e culturais que contribuíram ou determinaram as discussões críticas sobre a "morte do romance", isto é, a saturação do gênero romanesco no contexto das produções literárias moderna e contemporânea. À vista disso, pretendese explorar se há de fato uma queda ou infertilidade na composição romanesca, ou se existe efetivamente um esforço consciente e deliberado de autores das mais diversas nacionalidades e tradições para uma reformulação da estrutura do romance.

Palavras-chave: romance; contemporaneidade; morte do romance; romance geopolítico; obra-mundo.

Abstract: This paper aims to analyze briefly the formal changes as well as the historical and cultural background which have contributed or determined critical discussions about the "death of the novel", namely, the exhaustion of this literary genre within the range of modern and contemporary literary compositions. Thence, this analysis aims to explore if there is indeed a downsize or even a lack of creativity in the contemporary literary production, or if there is a deliberate and conscious attempt by authors from different origins and traditions in order to reformulate the structure of the novel.

Keywords: novel; contemporaneity; death of the novel; geopolitical novel; worldsystem. 


\section{Introdução}

O presente artigo busca analisar histórica e criticamente a forma como se desenvolveu o conceito, ou por vezes a impressão um tanto vaga, da "morte do romance", isto é, seu exaurimento e palidez perante outros modos de narrativa ou experiência estética. Todavia, conforme os autores e a bibliografia que elencamos ao longo do texto evidenciam, a questão da morte do romance, ou mais amplamente a morte da literatura, tornou-se não somente um catalisador ou "hormônio" de criação poética e romanesca, mas é, de igual modo, uma experiência recorrente e presente desde os primórdios do romance.

Desse modo, mais do que um presságio temerário de profetas literários, a ideia da morte da literatura é o resultado de diversos fatores, circunstâncias e pressupostos que constituem o próprio cerne do pensamento ocidental desde fins do século XVIII, nomeadamente, a derrubada e descrédito das grandes instituições fornecedoras de sentido à vida e às obras humanas, o esvaziamento da linguagem em contraposição ao domínio científico sobre a natureza, o surgimento dos Estados burocratizados e alguns posteriormente totalitários, e, por fim, a capacidade efetiva - oriunda da expansão da tecnocracia - de aniquilamento do próprio homem por meio de suas próprias criações e instrumentos.

Entretanto, se considerarmos detalhadamente sua evolução, o romance - e a literatura como um todo - valeu-se ao longo do tempo de novos modos de narração, distintas percepções espaço-temporais e um senso agudo das transformações e tensões políticas em âmbito global, isto é, os romances não mais retratam, no entendimento de Flaubert, a vida privada de suas nações, mas também as inter-relações - públicas e privadas - de todas as nações.

Se Édouard Glissant ${ }^{1}$ dizia que todo poeta contemporâneo, mesmo o monolíngue, deve, necessariamente, escrever perante e levando em consideração todas as demais linguagens, também o romancista, mesmo aquele que obsessivamente descreve, radiografa e compreende seu próprio país (como é o caso de um Lobo Antunes, um Philip Roth, na contemporaneidade), deve escrever levando em conta as "entranhas" de todos os demais países.

${ }^{1}$ GLISSANT. Introdução a uma poética da diversidade, p. 30. 


\section{História de um epitáfio}

Qualquer tentativa de apreensão daquilo que já se convencionou chamar de "morte do romance" requer, em primeiro lugar, a referência aos elementos do romance que se julgam desgastados. Isto é, via de regra, alguns críticos, como Claes Ryn, entendem que o romance, sendo uma radiografia de um destino individual e suas relações de confronto ou apoio com a sociedade na qual está integrado, tornou-se um sibila muda, não possuindo nada mais de novo a narrar, já que todas as narrativas possíveis já foram escritas.

Por outro lado, há críticos que compreendem que o romance, especificamente em sua forma, implodiu suas próprias estruturas mediante a repetição, tendo se reduzido, portanto, a uma fórmula pronta, como é o caso de John Barth e James W. Hall. E, evidentemente, há uma parcela de $\operatorname{críticos}^{2}$ que, assumindo o caráter indissociável do binômio forma $\mathrm{x}$ conteúdo, declaram que o romance, como um todo, está fadado ao desaparecimento.

Contudo, os escritores, seguindo o conselho de Jorge Luis Borges de que a literatura se esforça sempre para não se acomodar à teoria, atuam, desde sempre, em projetos para insuflar vitalidade ou renovar o gênero romanesco. Os teóricos do pós-modernismo, com o conceito do "fim das grandes narrativas", contribuíram não pouco para a ideia, talvez generalizada, segundo a qual não há mais narrativas possíveis.

A ironia é que esse sentimento de que "não há nada de novo debaixo do sol", já presente no Eclesiastes há três mil anos atrás, antes mesmo de configurar-se como teoria ou conceito, é uma experiência humana recorrente, e precisamente por esta razão um catalisador da criatividade. E efetivamente, como descreve Leyla Perrone-Moisés em seu ensaio "O longo adeus à literatura", tratando justamente das sentenças de morte pronunciadas não apenas contra o romance, mas também a literatura:

Quando se fala do fim da literatura, trata-se do fim de um tipo de literatura: aquela da modernidade. É evidente que algo mudou, e muito, na esfera literária. Os leitores talvez tenham mudado mais do que os escritores. As novas gerações não querem mais ler aquilo que os teóricos do século 20 chamavam de literatura.

\footnotetext{
${ }^{2}$ Dentre a qual podemos citar: Alfonso Berardinelli, W. Marx, R. Millet e B. Levinson.
} 
Por falta de critérios estáveis de avaliação, os críticos literários calaram-se, perderam espaço e prestígio. [...] O que aconteceu? A situação em que se encontra hoje a literatura não é a de uma ruptura, como a ocorrida entre o classicismo e o romantismo. Não se trata de uma simples oposição ao que havia antes. Boa parte da literatura atual vive da referência àquela que a precedeu, a da modernidade, que nela sobrevive na forma de citação, alusão, pastiche ou intertextualidade. Sua própria designação, literatura pós-moderna, a amarra à anterior. É uma literatura póstuma, uma literatura do adeus. ${ }^{3}$

Logo em seguida, a autora cita vários nomes de escritores cujas obras se valem justamente da temática da exaustão da literatura como motivo central de criação: Dublinesca e $O$ mal de Montano, ambos de Enrique Vila-Matas, em meio a outros nomes como Le Clézio e David Lodge.

Na verdade, a ideia da morte da literatura está indissociavelmente ligada ao conceito de decadência cultural ou civilizacional. Arthur Herman, em A ideia de decadência na história ocidental (1999), realiza um panorama dos pensadores e artistas que auxiliaram na fixação da expectativa ou conceito do fim da civilização. Os símbolos de todas as grandes culturas sempre deram testemunho da experiência de que se vive num presente pálido em relação a um passado glorioso, de maneira que o homem, com raras exceções, concebe invariavelmente sua época como decadente.

Todavia, conforme demonstra Herman, a escatologia deu lugar a um pessimismo histórico: dito de outro modo, a esperança apocalíptica ou palingenética foi substituída pela imanentização da história, instaurando assim uma concepção da história como processo fixo e regido por leis incontornáveis que eventualmente esgotar-se-ão.

No entanto, pode-se indagar, se essa experiência da decadência é recorrente em todas as épocas, existe a possibilidade duma relação entre ela e a morte da literatura? A questão, conforme sinalizada por Herman, é que, desde a modernidade, os pensadores, tendo ampliado o escopo de seu pensamento para incluir os demais povos, culturas e civilizações, propuseram uma crítica da totalidade das coisas.

${ }^{3}$ PERRONE-MOISÉS. O longo adeus à literatura, p. 1-2. 
É o caso de Friedrich Nietzsche, que acusava os europeus de estarem "doentes de história" e por levarem essa e outras doenças espirituais aos demais povos; Sigmund Freud advogava a ideia de que a civilização é fruto da repressão do impulso de agressividade e, portanto, a razão do mal-estar moderno. Isto sem contar as obras de Arnold Toynbee, Henry Adams e principalmente Oswald Spengler, os quais analisam e integram numa totalidade explicativa as marchas, progressos e destruições de todos os grandes movimentos e povos.

Ademais, embora a esperança ou temor apocalípticos sempre tenham povoado a mentalidade do homem, em especial o indivíduo ocidental, é somente na modernidade, entretanto, que a humanidade adquiriu, conquistou e forjou os meios e instrumentos para efetivamente promover o eschaton. Clausewitz tratou do conceito de "guerra total", e as duas grandes guerras foram as primeiras a envolver os grandes "agentes históricos" do Ocidente; a Guerra Fria e sua polarização geopolítica atuaram literalmente como o marco divisório do século XX; e, por fim, a crise atômica, a demonstração niilista de poder em Hiroshima, e o poder nuclear que é a primeira possibilidade concreta de destruição absoluta.

Neste contexto, a teleologia é interrompida e desacreditada, dando lugar ou ao sentimento de "fim de história", proposto (e posteriormente rejeitado) por Francis Fukuyama, segundo o qual todas as nações eventualmente convergiriam para um modelo semelhante de governo (no caso, a democracia liberal) e valores convergentes, ou na esperança utópica sempre procrastinada.

De toda forma, antes disso, logo nos primeiros anos do século XX, D. H. Lawrence, por exemplo, num ensaio tratando de Ulysses, de James Joyce, intitulado "Surgery for the novel - or a bomb", de 1923, tratou sobre "o leito de morte do romance ponderado", um paciente precocemente senil, o qual poderia ser curado somente com "uma convulsão ou um cataclismo". ${ }^{4}$

De semelhante modo, Walter Reed, em seu artigo "Don Quixote: The Birth, Rise and Death of the Novel", 5 assinala que, embora a primeira parte da obra de Cervantes tenha inaugurado, segundo o entendimento de alguns críticos, o gênero romanesco, a segunda parte, publicada em 1615, já apresentava em si, codificada e embutida, a morte do gênero.

\footnotetext{
${ }^{4}$ LAWRENCE. The Future of the Novel (Surgery for the Novel - Or a Bomb), p. 152.

${ }^{5}$ REED. Don Quixote: The Birth, Rise, and Death of the Novel, p. 263-278.
} 
John Barth, em seu romance epistolar Letters (1981), cita uma carta de Samuel Richardson, de 1758, no qual dá a entender que o romance é uma "moda ultrapassada"; 6 e o próprio Barth é talvez a principal referência, no século $X X$, no que diz respeito ao suspiro da literatura.

Em seu ensaio "The Literature of Exhaustion" [A Literatura da Exaustão], de 1984, Barth afirma o seguinte:

Formas literárias certamente possuem histórias e contingências históricas, e pode muito bem ser que o tempo do romance como uma forma de arte superior tenha chegado ao fim, como se deu com os "tempos" da tragédia clássica e as grandes óperas da Itália e Alemanha, ou com as sequências de sonetos. Não há nisto, contudo, motivo nenhum para alarme, exceto talvez para certos romancistas, e um modo de lidar com um sentimento pode ser escrever um romance sobre ele. Parece-me irrelevante se, historicamente, o romance expirará ou sobreviverá; se um número suficiente de escritores e críticos se sentem apocalíticos quanto a isso, o sentimento deles se torna um fato cultural relevante, assim como o sentimento de que a civilização ocidental, ou o mundo, terminará em breve. ${ }^{7}$

Com o passar do tempo, contudo, Barth revê suas ideias e redige o ensaio "The Literature of Replenishment" [A Literatura do Reabastecimento], publicado originalmente em 1982, no qual lança as bases de seu entendimento sobre o pós-modernismo, que considerou um movimento esteticamente fértil e inovador. De todo modo, mesmo George Orwell, em ensaio de 1936, "In Defense of the Novel" [Em Defesa do Romance], aponta para a desqualificação, por parte dos intelectuais, tanto dos romances quanto de seus leitores. Aparentemente, a popularização

\footnotetext{
6 “[...] worn-out fad" (BARTH. Letters. p. 427, tradução minha).

7 "Literary forms certainly have histories and historical contingencies, and it may well be that the novel's time as a major art form is up, as the "times" of classical tragedy, Italian and German grand opera, or the sonnet-sequence came to be. No necessary cause for alarm in this at all, except perhaps to certain novelists, and one way to handle such a feeling might be to write a novel about it. Whether historically the novel expires or persists as a major art form seems immaterial to me; if enough writers and critics feel apocalyptical about it, their feeling becomes a considerable cultural fact, like the feeling that Western civilization, or the world, is going to end rather soon". (BARTH. The Literature of Exhaustion, p. 62-76, tradução minha)
} 
(dado inerente ao romance, que é o produto da alfabetização massiva e da ascensão da burguesia) do gênero culminou em sua degradação:

É quase desnecessário assinalar que, no atual momento, é pequeno o prestígio do romance, tão pequeno que as palavras "Eu jamais leio romances", que alguns anos atrás seriam, em geral, expressas com uma indicação de desculpas, são agora pronunciadas num tom de orgulho consciente [...] Mesmo presentemente o romance se deteriora de modo visível, e deterioraria ainda mais rapidamente, se a maior parte dos romancistas tivesse alguma ideia de quem lê seus livros. Evidentemente é fácil dizer (vide, por exemplo, o ensaio grotescamente rancoroso de Belloc) que o romance é uma forma desprezível de arte e que seu futuro não importa. Eu duvido que essa opinião é sequer digna de atenção. De todo modo, tomo como certo de que vale a pena salvar o romance, e que a fim de salvá-lo é necessário persuadir pessoas inteligentes a tomá-lo seriamente. Vale, pois, a pena analisar uma das várias causas - em minha opinião, a principal causa - da queda do prestígio do romance. ${ }^{8}$

Em seguida, Orwell trata da principal razão pela qual o romance caiu em desprestígio e não é mais digno de ser lido, ao menos pelas pessoas inteligentes de sua época - a publicação em massa impede ou dificulta a apreciação e hierarquização dos romances dignos de serem lidos.

Todavia, mais recentemente, nomes como Alfonso Berardinelli defendem que "o romance - a forma literária mais moderna e democrática - estaria sendo dificultado, se não morto, pela democracia moderna”, pois

\footnotetext{
8 "It hardly needs pointing out that at this moment the prestige of the novel is extremely low, so low that the words 'I never read novels', which even a dozen years ago were generally uttered with a hint of apology, are now always uttered in a tone of conscious pride $[\ldots]$ Even now the novel is visibly deteriorating, and it would deteriorate much faster if most novelists had any idea who reads their books. It is, of course, easy to argue (vide for instance Belloc's queerly rancorous essay) that the novel is a contemptible form of art and that its fate does not matter. I doubt whether that opinion is even worth disputing. At any rate, I am taking it for granted that the novel is worth salvaging and that in order to salvage it you have got to persuade intelligent people to take it seriously. It is there fore worth while to analyze one of the many causes - in my opinion, the main cause - of the novel's lapse in prestige". (ORWELL. In defense of the novel, p. 137-140, tradução minha)
} 
paulatinamente vem perdendo "sua incisividade [...] de marcar a fundo a consciência cultural de intelectuais, escritores e leitores comuns".

A posição de Berardinelli é inusitada, pois coloca como fator destrutivo do romance precisamente o componente que o tornou possível: a democracia. Mas, de fato, seu raciocínio leva em conta as circunstâncias concretas atuais, pois, se o romance é, na concepção de alguns, o principal produto cultural da ascensão da democracia moderna (Ian Watts, Hegel), então, por analogia, a crise da democracia - isto é, o crescimento da suspeita de sua genuína representatividade e promoção das liberdades individuais - caminha concomitantemente com a crise do romance.

Assim como no caso da democracia, indaga-se ao romance se ele ainda é capaz de representar uma sociedade cada vez mais pluralista e heterogênea; e se, em vez de celebrar a individualidade e liberdade humanas, como em seus primórdios, não tem recaído constantemente na declaração, um tanto resignada, da fragilidade não só do indivíduo, mas também das comunidades, perante as forças geopolíticas, cósmicas e globais, conscientes e inconscientes, que atuam de modo inexorável ou inapreensível.

\section{As possíveis causas da morte do romance}

De modo que nos resta saber se a literatura contemporânea tem acompanhado o processo que por vezes avança, por outras retrocede, do conhecimento de si mesmo por parte do homem. É inegável que o progresso tecnocientífico não traz consigo, necessariamente, o progresso moral. Em alguns casos extremos, como a já citada Hiroshima, é possível contemplar um imenso abismo entre ambas as instâncias (a moral e a tecnocientífica); e é, portanto, nessa lacuna que alguns romancistas contemporâneos, dentre eles Lobo Antunes, fundam seu projeto literário.

De igual modo, a crise do romance, num primeiro nível, está ligada à crise da linguagem, ou, antes, seu agravamento, visto que desde Mallarmé, literariamente falando, os autores percebem a exaustão da linguagem e trabalham em prol da renovação do sopro primordial e do retorno da "língua da tribo". A descrença nos poderes comunicativos e referenciais da palavra e a degradação da linguagem simbólica da literatura em autismo estético constituem-se razões suficientes para

${ }^{9}$ BERARDINELLI. Não incentivem o romance e outros ensaios, p. 172. 
advogar a morte do romance. Richard Sheppard, em seu ensaio "A crise da linguagem", comenta:

Com ou sem razão, muitos escritores modernos sentem que o discurso comum é mutiladoramente insuficiente. As palavras penetram a tal ponto na realidade que se torna necessário investir contra a linguagem, "a pior das convenções", para que ela possa voltar a ser uma lente a revelar um tiers aspect perdido. Daí deriva a noção especificamente moderna da linguagem literária como "autotélica". Como a linguagem convencional é considerada "despotenciada", "dessubstancializada" e esvaziada, rejeita-se a sua sintaxe e vocabulário por serem imprestáveis para a poesia. ${ }^{10}$

Numa perspectiva mais ampla, a crise da linguagem se encontra profundamente entremeada com a crise e falências das instituições e tradições. À medida que as tradições e narrativas fundantes de uma sociedade são destituídas de sua substancialidade e substituídas pelo discurso supostamente objetivo e neutro da ciência, a própria linguagem literária se vê ameaçada; afinal, a literatura que adota a linguagem matematizada da ciência aniquila a possibilidade mesma de sua existência. Sem ambiguidade, ambivalência e uma estrutura mais simbólica do que lógica, tanto a prosa quanto a poesia são negadas.

Um componente integrante da crise moderna da linguagem é a separação entre discurso social e discurso literário. Enquanto a "superfície" do texto clássico deriva sua força e corresponde-se com a autenticidade das estruturas sociais e linguísticas por ele pressupostas e enaltecidas, o escritor moderno não tem como pretender tal correspondência. Antes de poder criar um "ícone verbal" adequado, ele precisa desmontar as estruturas do mundo convencional e "fazer explodir" a linguagem. ${ }^{11}$

O descompasso da linguagem romanesca e o discurso oficial em romances como Da Natureza dos Deuses (Lobo Antunes), À Espera dos Bárbaros (Coetzee) e Vestígios do Dia (Kazuo Ishiguro) é evidente na medida em que a linguagem homogênea e dissimuladora do autoritarismo (comum a todos essas obras) é implodida mediante a repetição, a alegoria e o relato paralelo de subalternos. No entanto, esse desencontro ou

\footnotetext{
${ }^{10}$ SHEPPARD. A crise da linguagem, p. 268.

${ }^{11}$ SHEPPARD. A crise da linguagem, p. 268.
} 
desarmonia gera precisamente a dissonância característica da obra de modernos e pós-modernos.

Em outros termos, a atual disparidade entre as narrativas de unificação ou fundação sociais e a narrativa romanesca, embora produza certa descrença no potencial da literatura, é, todavia, reaproveitada pelos escritores como elemento estético que representa, em si mesmo, a paralaxe do mundo moderno, no qual a possibilidade mesma do discurso oficial se dá com a negação ou supressão da individualidade, quando não do indivíduo.

Nesse sentido, é interessante perceber como pensadores dos mais diferentes espectros políticos chamam a atenção para a expansão totalitária em escala global e para o permanente "estado de exceção" (Giorgio Agamben) em que vivemos.

Para Carl Schmitt, por exemplo, que lançou esta última problemática, o estado de exceção dá luz ao soberano, pois é ele quem dita o direito; Claes G. Ryn, de semelhante modo, designa o desapego dos Estados Unidos da América aos seus valores fundantes de "novo jacobinismo", um estado permanentemente revolucionário, ainda que formalmente legítimo; e, por fim, temos também o conceito proposto em 2003, pelo filósofo político Sheldon Wolin, de "totalitarismo invertido", o qual é utilizado para se referir aos movimentos e ações políticas dentro dos Estados Unidos da América, por parte de grandes corporações, para subverter a ordem liberal de forma semelhante ao nazismo.

O "totalitarismo invertido", como o próprio nome permite entrever, inverte a ordem das coisas, quase uma consecução do alerta de Aldous Huxley, em seu prefácio a Admirável mundo novo, sobre a nova ditadura que não precisaria se impor sobre seus dóceis escravos, visto que submeter-se-iam de bom grado. ${ }^{12}$

12 "Não há nenhuma razão, bem entendido, para que os novos totalitarismos se pareçam com os antigos. O governo por meio de cacetes e de pelotões de execução, de fomes artificiais, de detenções e deportações em massa não é somente desumano (parece que isso não inquieta muitas pessoas, atualmente); é - pode demonstrar-se - ineficaz. E numa era de técnica avançada a ineficácia é pecado contra o Espírito Santo. Um estado totalitário verdadeiramente 'eficiente' será aquele em que o todo-poderoso comitê executivo dos chefes políticos e o seu exército de diretores terá o controle de uma população de escravos que será inútil constranger, pois todos eles terão amor à sua servidão. Fazer que eles a amem, tal será a tarefa, atribuída nos estados totalitários de hoje aos ministérios de propaganda, aos redatores-chefes dos jornais e aos mestresescolas" (HUXLEY. Admirável mundo novo, p. 11) 
Tudo isto, quase que necessariamente, culmina numa questão ainda mais profunda - na realidade, uma crise da qual ainda sentimos a vertigem e não foi respondida satisfatoriamente. A morte do romance está também intimamente ligada à crise do homem, ou como alguns já designam, o pós-humano. Antes um conceito originalmente ligado à ficção científica tornou-se, hoje, por meio da entronização da técnica, um elemento no campo das possibilidades. Desde o ensaio que utilizou pela primeira vez o termo, isto é, "Prometheus as Performer: Toward a Posthumanist Culture", do crítico Ihab Hassan, em 1977, e em seguida, pelo "Posthuman Manifesto", em 1988, o que se desenvolveu nas diversas antropologias (inclusive a teológica, como é o caso do jesuíta Teilhard de Chardin, com sua teoria evolucionista-transcendental do Ponto Ômega, um paroxismo cósmico da evolução humana) foi, por um lado, uma crença otimista no potencial meliorista do homem, e, por outro, um niilismo gnóstico que despreza as limitações físicas e emocionais humanas.

A própria consciência, por exemplo, é analisada mediante a analogia cibernética e dos dados virtuais, sendo, habitualmente, reduzida, ainda que de forma metafórica, a pacotes (quanta) de informação. Evidentemente, um conceito que, num primeiro momento, parece-nos anódino, desgarrase, em verdade, numa senda nociva, pois se a consciência humana, e seu aspecto mais valioso, a saber, a autoconsciência, pode ser reduzido a um mero fluxo de informações, segue-se que a culpa, a empatia e o senso de dever são manipuláveis ou passíveis de serem reescritos arbitrariamente. $\mathrm{O}$ perigo da concepção pós-humanista ${ }^{13}$ é que ele sempre pressupõe uma instância modeladora - e, por definição, aperfeiçoadora -, a qual invariavelmente é o Estado moderno. É por isso que James Wood, numa sua obra, classificou grande parte da produção romanesca contemporânea de realismo histérico - o excesso de informações que caminha de mãos dadas e na mesma proporção que o crescimento da paranoia.

\section{Ressurreição do romance ou um novo gênero?}

Retornando à questão propriamente formal da morte ou ao menos exaustão do gênero romanesco, é interessante notar como o crítico

\footnotetext{
${ }^{13}$ Nesse sentido, o pós-humanismo e a geopolítica caminham paralelamente, visto que, esta última sempre encara o Estado não como uma entidade definida ou minimamente estável, mas como um órgão dinâmico e em constante crescimento.
} 
húngaro Ferenc Fehér, discípulo de Lukacs, em seu livro O romance está morrendo?, publicado originalmente em 1972, já combatia a tese, em voga desde então, da morte do romance. Sua argumentação, de fato valiosa, atesta que o romance é essencialmente ambivalente, ou, dito de outro modo, sua força criativa provém justamente de sua contradição interna, pois, emergindo da classe burguesa, é também seu principal crítico.

Nascendo da reflexão e do imaginário da sociedade burguesa, o romance, por outro lado, todavia, descreve e revela as tensões do seu meio de origem. Nessa autofagia contínua, o romance encontra na negação e reafirmação de valores e mesmo formas, e também no conflito consigo mesmo, a base para sua permanência.

A argumentação essencial de Fehér, apesar de parcialmente datada, é ainda válida; porém a forma como o romance se relaciona com seu meio ou com os demais meios que surgiram nos últimos 40 anos tornou-se mais complexa e circunstancial. Em determinada passagem de seu livro, Fehér afirma:

A ruptura entre o Eu e o mundo exterior se mostra da maneira mais crua nesta dimensão da representação, que, em seus primeiros instantes, manifestara com mais veemência a supremacia do gênero épico novo sobre o antigo: o homem do romance não sabe mais o que fazer com as instituições de seu mundo, ele as experimenta como sempre mais transcendentais em relação à sua própria qualidade empírica (daí a verdade profunda de um Kafka) para acabar, simplesmente, por esquecê-las, ou pelo menos, esforçar-se no sentido de esquecê-las. ${ }^{14}$

De fato, no romance contemporâneo, o indivíduo efetivamente experimenta as instituições de seu mundo não mais como suportes para seu crescimento ou caminhada, mas como elementos simbólicos que transcendem a própria percepção; no entanto, diferente do parecer do crítico, não é mais possível ignorá-las, já que, embora sua essência permaneça sempre inapreensível empiricamente, seus meios de ação são concretos, intrusivos e visíveis na totalidade da vida, mesmo nas relações e aspectos mais íntimos.

De modo que, mais do que nunca, o discurso literário e o discurso institucional não apenas divergem, mas se opõem frontalmente. Nesse

${ }^{14}$ FEHÉR. O romance está morrendo?, p. 29. 
sentido, ao menos politicamente falando, se compararmos o romance e a narrativa oficial, torna-se clara a impotência prática daquele no que diz respeito ao poder de legitimação. Portanto, nesta "era das revoluções", aqueles que conhecem o papel do romance no imaginário e rupturas históricas passadas, o potencial subversivo do romance é agora nulo.

Em outra passagem significativa de sua obra, Fehér aponta para o aspecto autônomo do romance, a liberdade formal e conteudística que se espelha no destino aberto ao protagonista, analogia das possibilidades de ascensão social então vigentes com a burguesia:

Todo romance digno deste nome, independentemente da ideologia que manifesta e torna seu autor mais perspicaz, ou pelo contrário, mais cego, faz a pergunta: que pode o homem fazer de si mesmo? As respostas podem estar cheias de esperança ou ser desencorajadas, o resultado final pode ser a vitória ou a derrota da humanidade, mas o processo em si, no seio do qual um homem se acha ou se perde, se cria ou se destrói, representa um valor de humanização que supera amplamente a função da epopeia. Além disso, e justamente porque o romance parte do indivíduo fortuito, logo do tema da liberdade ilusória, o resultado do processo de educação é ambivalente não só em relação a uma situação concreta, mas também teórica e genericamente. É por isso que a tomada de posição da alternativa está expressa na visão do mundo do romance em oposição à predestinação da epopeia. ${ }^{15}$

O crítico contrapõe acertadamente a liberdade e autonomia constituintes do imaginário romanesco, que são metaforizados na ação do personagem, com a predestinação da epopeia, na qual o protagonista, mais uma metonímia da coletividade do que uma individualidade integral, é, desde sua gênese, preparado para a consecução de uma tarefa ou vitória divina ou transcendentalmente preordenada, um destino que revela uma continuidade axial entre o tempo e o mito.

Poderíamos também contrapor essa liberdade e autonomia ao fatalismo da tragédia, na qual um indivíduo, não raro um estrangeiro não afeito às leis locais, mas ainda assim apegado às leis transcendentais, se depara com uma série de eventos divinamente estabelecidos, mas nem por isso inteligíveis.

${ }^{15}$ FEHÉR. O romance está morrendo?, p. 63, grifos do autor. 
$\mathrm{Na}$ tragédia, não há predestinação, mas fatalismo, visto que o gênero testemunha a falência ou colapso do indivíduo perante uma lei divina ou estatal inescapável. Mas se no épico, o protagonista é, de certo modo, consciente de seu dever e também de sua genealogia, a qual é causa e suporte para seu sucesso, e se na tragédia, o personagem principal percebe a série de ações que realiza somente numa perspectiva obscurecida, incapaz de alterá-la, nos primórdios do romance, todavia, não há leis transcendentes, no máximo econômicas, isto é, imanentes e cognoscíveis, que por vezes podem ser alteradas, ampliadas ou negadas a seu bel-prazer, e o destino do indivíduo pertence e depende de sua iniciativa e independência. Ele não é um herói predestinado nem fadado, mas fortuito, lutando e se apoiando não nas instituições ou leis, mas nas circunstâncias. Portanto, não há uma diretriz superior ou anterior, sua volição é o fator determinante e intérprete da objetividade do real. Como Roger Kimball, em seu artigo "A importância de T.E. Hulme", reunido na obra Experimentos contra a realidade: o destino da cultura na pós-modernidade:

"A raiz de todo romantismo", para Hulme, era a crença de que "o homem, o indivíduo, é um reservatório infinito de possibilidades; e de que, se for possível reorganizar a sociedade através da destruição da ordem opressiva, então essas possibilidades terão uma chance e assim se chegará ao Progresso". ${ }^{16}$

Todavia, há atualmente um componente que torna a situação ainda mais complexa: desde o "fim das certezas" (Ilya Prigogine), a predominância do desconstrucionismo e o estabelecimento, no âmbito das ciências naturais, da física de Planck e Einstein (no âmbito micro e macro, respectivamente), os conceitos da incerteza, probabilidade, acaso e imprevisível passam a integrar o ideário ocidental, atuando como instrumentos e métodos de aferição e interpretação da totalidade dos fenômenos.

O que está em jogo não é mais somente o "caráter fortuito do indivíduo", mas também o aparente aspecto contingente dos fenômenos reais e suas relações. O protagonismo do romance se dá com um indivíduo fortuito imerso num plano, à primeira vista, regido pelo aleatório. E, é claro, um dos elementos que contribuíram para a fixação da noção

${ }^{16}$ KIMBALL. Experimentos contra a realidade, p. 66. 
da morte do romance no imaginário cultural e estético do Ocidente é precisamente a singular relação do indivíduo com seus objetos circundantes, a qual se desenvolveu ao longo do século XX.

Referimo-nos aqui àquilo que se convencionou designar de "obsolescência programada", a limitação deliberada da vida útil e funcionamento de determinados dispositivos. A analogia não é gratuita, conforme demonstra o título da obra de Kathleen Fitzpatrick, The Anxiety of Obsolescence: The American Novel in the Age of Television [A ansiedade de obsolescência: o romance norte-americano na era da televisão], publicado em 2006. Na época da obsolescência programada, em que os objetos de uso diário, e por isto mesmo personalizados, estão de antemão condenados a uma duração deliberadamente estabelecida, a cultura, tendo sido afetada, se tornou, à semelhança do conto de Hawthorne, "um holocausto da terra".

A duração predeterminada dos objetos conduz a um estado mental, no qual tudo, incluindo relações concretizadas, torna-se prescindível. Portanto, o romance, sendo um artefato cultural, possui de igual modo seu prazo de validade, que se esvai com o tempo ou com o uso.

Mas esse movimento de negação e fungibilidade remonta ao princípio mesmo do "moderno", pois, conforme assinala Compagnon em Cinco Paradoxos da Modernidade,

Na medida em que cada geração rompe com o passado, a própria ruptura constitui a tradição. Mas uma tradição da ruptura não é, necessariamente, ao mesmo tempo uma negação da tradição e uma negação da ruptura? A tradição moderna, escrevia Octavio Paz, em Ponto de Convergência, é uma tradição voltada contra si mesma, e esse paradoxo anuncia o destino da modernidade estética, contraditória em si mesma: ela afirma e nega ao mesmo tempo a arte, decreta simultaneamente sua vida e sua morte, sua grandeza e sua decadência. ${ }^{17}$

Portanto, tudo isto nos leva a pensar que o próprio discurso e celeuma no tocante à morte do romance é talvez um sinal de sua obstinação, traço de um remanescente de vitalidade. De fato, se fora um gênero já extinto, como supostamente é o caso da tragédia - segundo o polêmico epitáfio de George Steiner em sua obra The Death of Tragedy

${ }^{17}$ COMPAGNON. Os cinco paradoxos da modernidade, p. 10. 
[A Morte da Tragédia] (1974) -, possivelmente não deparar-nos-íamos com bibliografia e reflexões tão prenhes conforme a consulta mais superficial revela.

Ademais, é perceptível o esforço de vários escritores, por meio do experimentalismo e inovação, em negar ou postergar o fim do romance - seu trabalho é, pois, signo concreto de fertilidade. E, nada obstante, os atestados de óbito e epitáfios derradeiros não impedem eventuais ressurreições, pois, apesar das declarações da morte do gênero épico, o que dizer de Omeros, de Derek Walcott, laureado com o prêmio Nobel? Mas, ainda mais significativo, são dois conceitos então em voga que de fato levantam a questão mencionada no título: estamos perante uma ressurreição do romance ou uma nova forma, um pós-romance? No caso, referimo-nos ao romance geopolítico (Caren Irr) e à obra-mundo (Franco Moretti).

Publicado em 2014, o livro Toward the Geopolitical Novel (2014), de Caren Irr [Em direção ao romance geopolítico], expõe a dualidade e a tensão entre os blocos ideológicos que marcaram e formaram o Ocidente e os indivíduos isolados tecnologicamente no seio de suas comunidades. Nas palavras de Irr:

As perspectivas apresentadas no romance geopolítico não podem ser costumeiramente ligadas a um partido político particular, ou a um programa, ou repetido em slogans de manifestações urbanas; antes são padronizados e pautados em determinado princípio. O romance geopolítico trabalha com os blocos de construção das ideologias do século XXI. [...] Os conflitos ideológicos apresentados no romance geopolítico excedem as limitações impostas pela indústria editorial, os preconceitos arraigados dos leitores, e as influências dos recentes eventos marcantes. A ficção geopolítica cria um mundo vívido que aguarda ser mapeado e explorado. Trata-se de um mundo em formação, aberto ao futuro, e pronto para o total engajamento do leitor. A cultura, tomada como um processo ativo e contínuo, em vez de um museu de objetos seletos, segue progredindo no romance geopolítico do século XXI. ${ }^{18}$

18 "The visions offered in the geopolitical novel may not be routinely attached to a particular political party or program or repeated in the slogans of street protests, but they are patterned and principled. The geopolitical novel works with the building blocks of twenty-first-century ideologies [...] The ideological struggles expressed 
Assim, o escritor (e os leitores) vê-se premido pela exigência de respostas para as "ansiedades espaciais características do chamado planeta das favelas [Planet of Slums, nome de uma obra de Mike Davis] - isto é, um cenário global caracterizado pela urbanização e proletarização extremamente veloz, numa escala massiva". ${ }^{19}$ Nessa perspectiva, todos os dramas tornam-se potencialmente globais, não há mais um evento fundante de uma nacionalidade, porém há eventos que certamente fundem as diversas nacionalidades, como é o caso do terrorismo, que agora reúne sob uma mesma ansiedade os mais diversos países. Ademais, se, como diziam alguns críticos literários, o romance é um produto cristalizado de determinada ideologia - especialmente a burguesa -, qual é a possibilidade do romance numa era supostamente pós-ideológica e mesmo pós-utópica?

Pieter Vermeulen, em sua obra Contemporary Literature and the Death of the Novel [literatura contemporânea e a morte do romance] diz que essas condições listadas acima necessariamente conduzem a uma busca por uma nova forma literária global:

[Há] duas preocupações que movem os romances: a busca por uma forma literária adequada na qual registrar as complexidades da vida globalizada do século XXI, e a busca por um modo de se relacionar aos outros globais no conhecimento deficiente de que essas relações estão irrevogavelmente contaminadas pela cumplicidade desconfortável com a contínua violência da guerra e colonialismo. ${ }^{20}$

in the geopolitical novel exceed the constraints installed by the publishing industry, the ingrained prejudices of readers, and the influences of recent landmark events. Geopolitical fiction creates a vivid world waiting to be mapped and explored. This is a world in formation, open to the future, and ready for the reader's full engagement. Culture as an active, ongoing process rather than a museum of rarified objects in under way in the twenty-first-century geopolitical novel". (IRR. Toward the Geopolitical Novel, p. 22, tradução minha)

19 " [...] spatial anxieties characteristic of the so-called planet of slums - that is, a global scene characterized by ultra-rapid urbanization and proletarianization on a massive scale”. (IRR. Toward the Geopolitical Novel, p. 139, tradução minha)

20 "[...] two of the novel's animating concerns: finding an adequate literary form in which to register the complexities of early twenty-first-century globalized life, and finding a way to relate to global others in the disabling knowledge that these relations are irrevocably contaminated by one's uneasy complicity in the continued violence of 
À vista disso, talvez tenhamos já, ao menos desde o século XVIII, ao menos embrionariamente, uma nova forma - aquilo que Franco Moretti chama de obra-mundo (opere-mundi). O crítico italiano indaga: há uma classificação possível para obras como Fausto, Ulysses, A montanha mágica, O homem sem qualidades e Guerra e paz? Podese dizer que são simplesmente romances? Porém, mais do que obras de grande extensão e profunda erudição, são paradoxalmente projetos incompletos, permeados de respostas às circunstâncias e tensões de seu momento de composição, mas de igual modo carregados de questões e problemas formais, linguísticos, históricos e filosóficos, que se tornam ainda mais complexos quando integrados à trama épica que lhes é própria. Estes "épicos modernos revelam um tipo de antagonismo entre o substantivo e o adjetivo: uma discrepância entre a vontade totalizadora do épico e a realidade subdividida do mundo moderno. A imperfeição dos textos-mundo é o sinal perfeito de que eles vivem na história". ${ }^{21}$

A obra-mundo se define como tal precisamente porque leva em conta não mais as fronteiras ou instituições de sua nação (como de hábito faziam os românticos na época das unificações nacionais), mas o sistema de relações do mundo. Nas palavras de Moretti: "todos eles são textosmundo, cujo quadro geográfico de referência não é mais o Estado-nação, mas uma entidade mais ampla - um continente, ou o sistema mundial como um todo". ${ }^{22} \mathrm{O}$ conhecimento abarcado, assim como o cenário e o período temporal no qual os enredos transcorrem, são maximizados, não mais reduzidos às nacionalidades; antes, compreendem o mundo enquanto sistema.

Além disso, uma das características essenciais das obras-mundo é o que Moretti denomina de "diletantismo monumental", que, segundo ele,

war and colonialism" (VERMEULEN. Contemporary Literature and the Death of the Novel, p. 143, tradução minha).

21 "They reveal a kind of antagonism between the noun and the adjective: a discrepancy between the totalizing will of the epic and the subdivided reality of the modern world. The imperfection of world texts is the sure sign that they live in history" (MORETTI. Modern Epic: the world system from Goethe to Gabriel García Márquez, p. 5, tradução minha).

22 "They are all world texts, whose geographical frame of reference is no longer the nation-state, but a broader entity - a continent, or the world-system as a whole". (MORETTI. Modern Epic: the world system from Goethe to Gabriel Garcia Márquez, p. 50, tradução minha). 
É o projeto - e o problema - de todo o épico moderno, com seu desejo de reunir o que a história dividiu: conhecimento, ética, com sua arte; narrativa, drama, poesia lírica; literatura, música, pintura [...] É uma euforia ambivalente, contagiosa, com relação à qual, à medida em que o século XIX dá passagem ao século seguinte, poucos são capazes de resistir - é uma reação, acredito eu, à crescente divisão intelectual do trabalho. ${ }^{23}$

Em suma, é uma tentativa de "escritura secularizada", uma obra canônica que sintetize numa unidade tudo aquilo que o processo de modernização fragmentou e dividiu. Nesse sentido, cabe de fato a indagação se a obra-mundo é uma transformação, ou mesmo uma superação, do romance, ou ainda uma sua forma ressurreta. No entanto, é cabível a afirmação de que a literatura ainda se vale de suas sentenças para sua própria postergação.

\section{Considerações finais}

As linhas aqui elencadas, que conduzem a reflexões e dilemas presentemente incapazes de serem respondidos, permitem-nos dizer, numa paráfrase ao Evangelho, que o "romance não está morto, somente dorme". Entretanto, a simples afirmação de que o romance continua vigoroso e que superou todos os momentos de saturação e desgaste seria ingenuidade, já que são claramente perceptíveis, ao longo da história da literatura, as alterações e mudanças (não necessariamente evolução) da composição e mesmo recepção do romance.

A mais superficial análise das obras de um Thomas Pynchon, ou de um David Foster Wallace, demonstram que há um rompimento consciente e deliberado da forma romanesca, assim como preocupações distintas daquelas que motivavam os romancistas modernos - mesmo os mais radicais e experimentalistas. Não se trata, evidentemente, conforme afirmamos acima, de um aperfeiçoamento do romance, mas sim de

23 "It is the project - and the problem - of the entire modern epic, with its desire to reunite what history has divided: knowledge, ethics, religion, art; narrative, drama, lyric poetry; literature, music, painting [...] It is a contagious, ambivalent euphoria that, as the nineteenth century gives way to the twentieth, very few can resist - in reaction, I believe, to the growing intellectual division of labour". (MORETTI. Modern Epic: the world system from Goethe to Gabriel García Márquez, p. 108, tradução minha) 
uma mudança em alguns pontos que até então eram basilares para sua composição.

O surgimento de um romance geopolítico ou a consecução dos projetos de obras-mundo são as respostas mais imediatas para alguns questionamentos que o público em geral, mas especialmente os próprios escritores, lançam à literatura. Certamente, a literatura sempre se moveu pautada pela autocrítica; no entanto, atualmente, vemos não mais uma tentativa de implosão da literatura (tal como houve uma antiarte nos meios dadaístas), mas uma crescente indiferença pelos seus mecanismos e respostas. Num mundo tomado por um cientificismo e por uma tecnocracia expansivos, a literatura, não se reduzindo jamais a uma técnica, luta por adequar-se às exigências e repensar suas próprias estruturas. Isto, contudo, é sinal de vitalidade, não de desfalecimento.

\section{Referências}

BARTH, John. Letters. Nova York: Book Sales, 1981.

BARTH, John. The Literature of Exhaustion. In: . The Friday Book: Essays and Other Nonfiction. Baltimore, MD: Johns Hopkins University Press, 1984. p. 62-76.

BERARDINELLI, Alfonso. Não incentivem o romance e outros ensaios. São Paulo: Nova Alexandria; Humanitas, 2007.

BORGES, Jorge Luis. Obras completas. São Paulo: Globo, 1999.

CLAUSEWITZ, Carl von. Da guerra. São Paulo: Martins Fontes, 2010. COMPAGNON, Antoine. Os cinco paradoxos da modernidade. Belo Horizonte: Editora UFMG, 2014.

FEHÉR, Ferenc. O romance está morrendo? Rio de Janeiro: Paz e Terra, 1972.

FUKUYAMA, Francis. O fim da história e o último homem. Rio de Janeiro: Rocco, 1992.

GLISSANT, Édouard. Introdução a uma poética da diversidade. Juiz de Fora: EDUFJF, 2005.

HALL, James W. Hit Lit: Cracking the Code of the Twentieth Century's Biggest Bestsellers. New York: Random House, 2012. 
HUXLEY, Aldous. Admirável Mundo Novo. São Paulo: Globo, 2002.

IRR, Caren. Toward the Geopolitical Novel: U.S. Fiction in the TwentyFirst Century. Nova York: Columbia University Press, 2014.

KIMBALL, Roger. Experimentos contra a realidade: o destino da cultura na pós-modernidade. São Paulo: É Realizações, 2016.

LAWRENCE, D. H. The Future of the Novel (Surgery for the Novel - Or a Bomb). In: . Study of Thomas Hardy and Other Essays. Cambridge: Cambridge University Press, 1985. p. 149-156.

LEVINSON, Brett. The ends of literature: The Latin American "Boom" in the Neoliberal Marketplace. Stanford/CA: Stanford University Press, 2002.

MARX, William. L'Adieu à la littérature - Histoire d'une dévalorisation, XVIIIe - XXe siècles. Paris: Les Éditions de Minuit, 2005.

MILLET, Richard. Désenchantement de la littérature. Paris: Gallimard, 2007.

MORETTI, Franco. Modern Epic: The World System from Goethe to Gabriel García Márquez. London/NewYork: Verso, 1996.

PERRONE-MOISÉS, Leyla. O longo adeus à literatura. Folha de S.Paulo, São Paulo, 10 jul. 2011.

PRIGOGINE, Ilya. O fim das certezas. São Paulo: Unesp, 1997.

REED, Walter. Don Quixote: The Birth, Rise, and Death of the Novel. Indiana Journal of Hispanic Literatures, v. 5, p. 263-278, 1994.

RYN, Claes G. The New Jacobinism: America as Revolutionary. Bowie/ Maryland: National Humanities Institute, 2011.

SCHMITT, Carl. Legality and legitimacy. London: Duke University, 2004.

SHEPPARD, Richard. A crise da linguagem. In: BRADBURY, Malcom; MCFARLANE, James. Modernismo guia geral: 1890-1930. São Paulo: Companhia das Letras, 1989. p. 263-274.

STEINER, George. The Death of Tragedy. London: Faber and Faber, 1974. 
VERMEULEN, Pieter. Contemporary Literature and the Death of the Novel. Hampshire: Palgrave Macmillan, 2015.

WOLIN, Sheldon S. Democracy Incorporated: Managed Democracy and the Specter of Inverted Totalitarianism. Princeton: Princeton University Press, 2017.

WOOD, James. Human, All Too Inhuman. The New Republic, Nova York, 24 jul. 2010. 